AperTO - Archivio Istituzionale Open Access dell'Università di Torino

\title{
Electrochemical analysis of microbial fuel cells based on enriched biofilm communities from freshwater sediment
}

\section{This is a pre print version of the following article:}

Original Citation:

Availability:

This version is available http://hdl.handle.net/2318/1647691

since 2017-09-15T13:15:14Z

Published version:

DOI:10.1016/j.electacta.2017.03.186

Terms of use:

Open Access

Anyone can freely access the full text of works made available as "Open Access". Works made available under a Creative Commons license can be used according to the terms and conditions of said license. Use of all other works requires consent of the right holder (author or publisher) if not exempted from copyright protection by the applicable law. 


\title{
Electrochemical analysis of microbial fuel cells based on enriched biofilm communities from freshwater sediment
}

\author{
Valeria Agostino, ${ }^{\mathrm{a}, \mathrm{b}}$, Daniyal Ahmed ${ }^{\mathrm{a}, \mathrm{b}}$, Adriano Sacco ${ }^{\mathrm{a},{ }^{*}, \text { Valentina Margaria }}{ }^{\mathrm{a}}$, Caterina \\ Armato $^{\mathrm{a}, \mathrm{c}}$, Marzia Quaglio ${ }^{\mathrm{a}}$ \\ ${ }^{a}$ Center for Sustainable Futures @ Polito, Istituto Italiano di Tecnologia, Corso Trento 21, 10129 Torino, Italy \\ ${ }^{b}$ Applied Science and Technology Department, Politecnico di Torino, Corso Duca degli Abruzzi 24, 10129 \\ Torino, Italy \\ ${ }^{c}$ Department of Public Health and Pediatrics, Università di Torino, Piazza Polonia 94, 10126 Torino, Italy \\ * Corresponding author: e-mail adriano.sacco@iit.it, Tel. +39 011 5091912, Fax. +39 0115091901.
}

\begin{abstract}
Microbial fuel cells (MFCs) are bioelectrochemical devices that directly convert the chemical energy stored in complex organic compounds into electricity, thanks to metabolic processes of electroactive microorganisms. In order to improve their performance, a complete understanding of the reactions that occur inside bioanodes is essential. Electrochemical Impedance Spectroscopy (EIS) represents a powerful method for the investigation of these biophysicochemical processes.

However, the larger part of EIS studies on MFCs proposed in the literature are often misconducted, employing cell configurations or measurement conditions which do not always allow obtaining reliable conclusions. In this work, EIS measurements, in three electrode configuration, were recorded as a function of different external resistances, to characterize and compare the impedance response of two different mixed-community microbial bioanodes coming from the same freshwater sediment sample but enriched with two different media, namely a general one and a $\mathrm{Fe}$ citrate one. In order to construct an appropriate equivalent electrical model and to give a right physical interpretation of the obtained results, focused control experiments in abiotic and starving conditions were performed.

Three processes were found to govern the bioanode impedance: a substrate/products diffusion process, a biofilm process and an electrode/electrolyte interfacial process. General-enriched bioanodes showed a more efficient electron transfer mechanism, with faster biofilm and diffusion time constants, lower resistance values and higher charge storage capacities. The maximum power point of general enriched biofilms $\left(51 \mathrm{~mW} / \mathrm{m}^{2}\right)$ occurred at an anode potential of $-0.4 \mathrm{~V}$; on the contrary Fe citrate enrichment resulted in a maximum power density of $26 \mathrm{~mW} / \mathrm{m}^{2}$. These results were in accordance with cyclic voltammetry analysis, that demonstrated a putative redox center of $-0.4 \mathrm{~V}$ for general enrichment and $-0.22 \mathrm{~V}$ for $\mathrm{Fe}$ citrate one.
\end{abstract}


Keywords: electrochemical impedance spectroscopy; microbial fuel cells; mixed community bioanodes; enrichment methods; equivalent electrical circuit.

\section{Introduction}

Electrochemical impedance spectroscopy (EIS) [1] is a well-established characterization technique, widely used to analyze different electrochemical systems and devices [2-5]. It imposes small potential perturbations to the system under study, thus representing a powerful and non-intrusive method for the testing and the diagnosis of bioelectrochemical systems (BES), including microbial fuel cells (MFCs) $[6,7]$. MFCs are a promising biotechnological approach able to directly convert the chemical energy stored in organic compounds into electrical energy, thanks to oxidation reactions catalyzed by microorganisms [8, 9]. The performance of these devices strongly depends on the bacterial composition of anodic biofilm (bioanode). Indeed, only a particular kind of microorganisms, namely exoelectrogens or anode-respiring bacteria, are able to transport the electrons outside their cell wall to reduce external acceptors, like metal-oxide minerals in natural environments, or anode electrodes in MFCs [10]. Understanding the bioelectrochemical reactions that govern bioanode system is crucial to enhance MFC operation and performance, and EIS demonstrated to be an effective tool in this analysis [6].

The majority of EIS studies on BES were conducted in whole cell configurations and in open circuit (OC) conditions, rarely giving useful information about electroactive microbial biofilms [11-14]. In fact, in order to investigate bioanodes' limiting processes, EIS measurements in 3-electrodes set-up and closed circuit conditions (i.e. at different anode potentials) should be performed. Recently, some research groups started focusing EIS analysis on the characterization of bioanode and biocathode separately, rather than investigating the whole cell [15]. This approach permitted the investigation of several features: the biofilm growth $[16,17]$, the electron transfer mechanisms in pure population bioanodes [18], or different parameters that could affect the charge transfer resistance $(\mathrm{pH}$ [19], electrode material [20], substrate and buffer concentrations [21]). However, in such works, the anodic or cathodic biofilms are usually studied in common electrochemical cell, instead of real operating MFCs [22], and the impedance characterization is always carried out by imposing polarization voltages [16, 18]. Sevda and coworkers [23] suggested to analyze the EIS response as a function of the external resistance, waiting for a cell potential steady state rather than forcing a polarization voltage. Especially when dealing with mixed microbial communities, whose kinetics are linked to a large number of factors, is very important to permit the biofilm stabilization. For this reason, performing EIS using the variable resistor method allows a more reliable observation of the device performance, thanks to the biofilm acclimation at a given potential.

In this study the analysis of EIS response of two different mixed-community microbial bioanodes is proposed. To the best of our knowledge, there are no works in the literature in which this kind of comparison is carried out. In particular, based on the aforementioned 
considerations, the bioanode EIS measurements were performed in 3-electrodes configuration as a function of the external resistances used during the polarization tests. This scheme was particularly designed with the aim to better understand how the bioanode impedance varies with respect to the polarization. In fact, by alternating the measure of cell voltages (both anode and total cell) and impedance response under the same applied load condition, no external perturbation is introduced to the system, thus allowing a real evaluation of the bioanode behavior. A great care must be taken to interpret EIS experimental data coming from microbial electrodes, because of the complexity of these biophysicochemical systems, that involve mechanisms not yet well established. For this reason, impedance spectra were recorded also in non-turnover (i.e. without the anodic organic substrate) and abiotic (i.e. in a biofilm-free device) conditions, in order to choose an effective equivalent electrical circuit (EEC) for the bioanode modeling, and to give a better interpretation of the obtained impedance data. Furthermore, cyclic voltammetry (CV) measurements and biofilm imaging were performed, to support the impedance characterization of mixed-community bioanodes.

\section{Materials and methods}

\subsection{Inoculum enrichment and biofilm formation}

A freshwater sediment sample (Bagnère creek, Valle D'Aosta, Italy) was enriched with two different media under anaerobic conditions: a Ferric Citrate $(\mathrm{FeC})$ medium and a General (Gen) medium. In both enrichment methods, sodium acetate was used as electron donor and carbon source. FeC medium consisted of: $\mathrm{Fe}(\mathrm{III})$ citrate $13.70 \mathrm{~g} / \mathrm{L} ; \mathrm{NaHCO}_{3} 2.50 \mathrm{~g} / \mathrm{L} ; \mathrm{NH}_{4} \mathrm{Cl}$ $1.50 \mathrm{~g} / \mathrm{L} ; \mathrm{NaH}_{2} \mathrm{PO}_{4} 0.60 \mathrm{~g} / \mathrm{L} ; \mathrm{KCl} 0.10 \mathrm{~g} / \mathrm{L} ; \mathrm{Na}$ acetate $2.50 \mathrm{~g} / \mathrm{L} ;$ Wolfe's Vitamin solution 10 $\mathrm{mL} / \mathrm{L}$ (ATCC) and Wolfe's trace mineral solution $10 \mathrm{~mL} / \mathrm{L}$ (ATCC). Gen medium consisted of: $\mathrm{NH}_{4} \mathrm{Cl} 1.50 \mathrm{~g} / \mathrm{L} ; \mathrm{NaH}_{2} \mathrm{PO}_{4} 2.45 \mathrm{~g} / \mathrm{L} ; \mathrm{Na}_{2} \mathrm{HPO}_{4} 4.28 \mathrm{~g} / \mathrm{L} ; \mathrm{KCl} 0.10 \mathrm{~g} / \mathrm{L} ; \mathrm{Na}$ acetate 2.50 $\mathrm{g} / \mathrm{L}$; Wolfe's Vitamin solution $10 \mathrm{~mL} / \mathrm{L}$ (ATCC) and Wolfe's trace mineral solution $10 \mathrm{~mL} / \mathrm{L}$ (ATCC). The microbial cultures were subjected to 3 sequential enrichments for 21 days of total growth.

Biofilm formation into the anodic chamber was carried out employing a low external resistance $(47 \Omega)$, resulting in a positive anode potential polarization.

\subsection{Microbial fuel cell setup and operation}

Experiments were conducted in two-chamber fuel cells (chamber volume $58 \mathrm{~mL}$ ), described in [24]. Briefly, a Cation Exchange Membrane (CEM, CMI-7000, Membranes International Inc., USA) was used to separate the two compartments; anode and cathode electrodes consisted of a carbon felt with an area of $38.5 \mathrm{~cm}^{2}$ (Soft felt SIGRATHERM GFA5, SGL Carbon, Germany); electrical contacts to the electrodes were made using graphite rods; an $\mathrm{Ag} / \mathrm{AgCl}$ reference electrode was inserted into the anodic chamber. A picture of the dualchamber MFC used is given in Fig. S1 of the Supporting Information (SI). 
The anolyte and the catholyte were continuously injected into the devices using multiple channel syringe pumps (NE1600, New Era Instrument, USA), with a hydraulic retention time of 5 days $(0.5 \mathrm{~mL} / \mathrm{h})$. The anodic organic substrate and the nitrogen source consisted of $1 \mathrm{~g} / \mathrm{L}$ per day of sodium acetate and $0.31 \mathrm{~g} / \mathrm{L}$ per day of ammonium chloride, respectively, dissolved into a phosphate buffer solution (PBS: $\mathrm{NaH}_{2} \mathrm{PO}_{4} 2.45 \mathrm{~g} / \mathrm{L} ; \mathrm{Na}_{2} \mathrm{HPO}_{4} 4.28 \mathrm{~g} / \mathrm{L} ; \mathrm{KCl}$ $0.10 \mathrm{~g} / \mathrm{L}$ ) with $10 \mathrm{~mL} / \mathrm{L}$ of Wolfe's Vitamin solution (ATCC) and $10.00 \mathrm{~mL} / \mathrm{L}$ Wolfe's trace mineral solution (ATCC). The cathode compartment was filled with potassium ferricyanide $(6.58 \mathrm{~g} / \mathrm{L})$ used as oxidant compound, dissolved into PBS.

For each enrichment method, two identical MFCs were prepared, thus conducting the experiments in duplicate. All the study was carried out at ambient temperature ranging from $20{ }^{\circ} \mathrm{C}$ to $22{ }^{\circ} \mathrm{C}$. A parallel abiotic test was performed under the same conditions.

\subsection{Electrochemical characterization}

Cell voltage across the external resistor and anodic potentials were continuously monitored using a data acquisition system (Agilent 34972A). At the end of biofilm acclimation phase (about 2 weeks, as reported below), polarization curves were obtained applying different external loads $(8.2 \mathrm{k} \Omega, 6.8 \mathrm{k} \Omega, 4.7 \mathrm{k} \Omega, 2.2 \mathrm{k} \Omega, 1.5 \mathrm{k} \Omega, 1 \mathrm{k} \Omega, 0.68 \mathrm{k} \Omega$ and $0.33 \mathrm{k} \Omega$ ) and measuring total cell voltage and anode voltage after stabilization. An additional point was measured at OC. To achieve steady electrochemical conditions, the cells were held at one resistance for approximately 1 day before switching to the next resistance value.

For each polarization condition, anode impedance spectra were recorded over a frequency range of $3 \mathrm{kHz}-3 \mathrm{mHz}$, with an $\mathrm{AC}$ signal having an amplitude of $25 \mathrm{mV}$, using a multichannel VSP potentiostat (BioLogic) in a 3-electrodes configuration (anode as working electrode, cathode as counter electrode, $\mathrm{Ag} / \mathrm{AgCl}$ into the anodic chamber as reference electrode). Additionally, EIS tests were carried out in abiotic and non-turnover conditions, in order to give a better interpretation of the obtained EIS experimental data.

After the polarization and EIS tests, $\mathrm{CV}$ was performed using the same potentiostat. The scan rate was $1 \mathrm{mV} / \mathrm{s}$, at potentials ranging from $-0.6 \mathrm{~V}$ to $0.2 \mathrm{~V}$ vs $\mathrm{Ag} / \mathrm{AgCl}$, and measurements were performed in turnover and non-turnover conditions. First derivatives of CV curves were calculated to obtain the putative electron transfer redox center $[25,26]$.

\subsection{Bioanode imaging}

Fluorescent microscopy (Nikon ECLIPSE Ni, Japan) was employed to characterize the biofilm distribution within the electrode. Prior to imaging analysis, anodes were stained using a LIVE/DEAD BacLight Bacterial Viability Kit (Invitrogen, CA). Briefly, carbon felt samples were washed in sterile PBS to eliminate the original medium, stained for $20 \mathrm{~min}$, and then re-washed in sterile PBS twice to eliminate excess dye. Imaging analysis was performed 
using NIS Elements Image Software; in particular, the automated spot count feature was used to estimate the number of live and dead microorganisms.

\section{Results and discussion}

\subsection{Bioanodes acclimation phase}

The freshwater sediment sample was enriched with the two chemical enrichment methods, namely $\mathrm{FeC}$ and Gen, based on series of anaerobic liquid cultures with acetate as electron donor. Difference between the two media consisted in the presence of Iron (III) Citrate in the FeC enrichment: this iron compound simulated the metal-oxide minerals that exoelectrogens used as electron acceptors in natural environments [27]. After 3 weeks of growth, the different enriched consortia were inoculated into the anode compartments of MFCs and voltage and current were acquired during the biofilm formation, as shown in Fig. 1. A lowvalue external load of $47 \Omega$ was used for biofilm formation. This acclimation method has been demonstrated to improve start-up and current generation of MFCs [28-30]. Once acclimated to the low resistances, the biofilms could sustain current generation even at larger anode potentials. In particular, this acclimation resulted in a positive anode potential polarization, as observed in Fig. 1. Gen-enriched bioanodes exhibited a faster start-up time compared to FeC-enriched ones. Specifically, after a 5 days start-up period, a steady state current density of $74 \pm 4 \mathrm{~mA} / \mathrm{m}^{2}$ and an anode potential of $0.173 \pm 0.012 \mathrm{~V}$ vs Ag/AgCl were obtained. On the contrary, FeC-enriched MFCs generated a lower current density of $50 \pm 3$ $\mathrm{mA} / \mathrm{m}^{2}$, with a start-up time of 10 days and a more positive anode potential of $0.224 \pm 0.015$ $\mathrm{V}$.

\subsection{Polarization curves}

Polarization tests were performed after the 2 weeks of stable current production. The bioanodes polarization curves obtained by using the variable resistor method are shown in Fig. 2. General enrichment resulted in better performances in terms of the maximum power density $\left(P_{\max }\right)$ and short circuit current density $\left(I_{\mathrm{sc}}\right)$ produced. The maximum power point (MPP) for both kinds of MFC occurred under an external resistance of $1 \mathrm{k} \Omega$. The $P_{\max }$ related to Gen-enriched bioanodes was the double of FeC ones, being $51 \pm 11 \mathrm{~mW} / \mathrm{m}^{2}$ and $26 \pm 1$ $\mathrm{mW} / \mathrm{m}^{2}$ respectively. As shown in Fig $2 \mathrm{~b}$, the anode potential corresponding to the MPP was different for the two enrichment methods: about $-0.4 \mathrm{~V}$ vs $\mathrm{Ag} / \mathrm{AgCl}$ for Gen-enriched bioanodes and $-0.3 \mathrm{~V}$ vs $\mathrm{Ag} / \mathrm{AgCl}$ for $\mathrm{FeC}$ ones.

\subsection{EIS analysis}

\subsubsection{Anode impedance spectra}


The impedance of bioanodes was evaluated under stable potential conditions as a function of the different applied external loads (from OC to $0.33 \mathrm{k} \Omega$ ). The Nyquist plots in Fig. 3 show how impedance varies with a change in anode polarization. More specifically, the total impedance decreased as the external resistance decreased until the MPP is reached (at $1 \mathrm{k} \Omega$ ) and then started to increase again. The internal resistance values at MPP did not match with the external resistance applied, contrarily to what happen in abiotic condition, as discussed below (Section 3.3.2). This points to the fact that the MPP observed in power densitypotential curves might actually not be due to an internal/external resistance matching, but to a reduced internal impedance, or in other words, to a more efficient performance of the biofilms at this rate of charge flow (current). Moreover, by comparing the spectra in Fig. 3a and Fig 3b, it can be observed how the two enrichment methods are different from each other: FeC-enriched bioanodes exhibited larger impedance values with respect to the Genenriched ones.

Usually, in EIS studies on MFCs, impedance spectra were represented with Nyquist plot, since it provides an immediate visualization of the total internal resistance values of the analyzed system $[21,22,31]$. On the contrary, Bode plots display magnitude and phase of the impedance as a function of frequency, allowing the analysis of the time constants related to the system under study. In particular, the phase shift is extremely important to identify the processes that govern the electrochemical response and to select an appropriate biophysicochemical model to fit EIS data. Fig. 4 reports the Bode plots related to the two enrichment methods under different polarization conditions (OC, $8.2 \mathrm{k} \Omega, 4.7 \mathrm{k} \Omega$ and $1 \mathrm{k} \Omega$ ). The separation between a high frequency peak $(1-5 \mathrm{~Hz})$ and a low frequency one $(10-100$ $\mathrm{mHz}$ ) can be appreciated. This distinction is more visible in OC conditions and in the FeCenriched bioanodes. However, as will become clearer below (Section 3.3.2), the low frequency feature is actually related to two different processes.

\subsubsection{Electrical model and interpretation}

An extremely important part of EIS analysis is the correct physical interpretation of the obtained results. Generally, more than one equivalent electrical circuit could fit experimental data: therefore, systematic changes in experimental conditions are essential to verify the validity of the electrical model to which the EIS results are compared. Therefore, in this study, impedance spectra were recorded also in abiotic and non-turnover conditions.

The results related to abiotic conditions are reported in Fig. 5 (Bode plots) and in Fig. S2 of the SI (Nyquist plot). Two different processes are visible, a high frequency one which can be associated to the charge transfer at the anode/solution interface and a low frequency one, which is associated to the diffusion of species in the electrolyte. It has to be highlighted that the latter is characterized by a potential dependence, while the former remains constant for all the potential conditions. Based on these considerations, the impedance data of the abiotic test were fitted through the equivalent circuit proposed in Fig. 6a, composed by an ohmic resistance in series with a Warburg diffusion element and a Voigt element; Table S1 reports the fitting values. Firstly, $R_{\mathrm{S}}$ is a series resistance related to the electrolyte solution in which the anode is immersed; $R_{\mathrm{S}}$ is not dependent on the polarization, with values of about $1 \Omega$ (not 
reported in Table S1). The high frequency interfacial process is modeled through the parallel combination of the charge transfer resistance $R_{1}$ and the Helmholtz layer capacitance $C_{1}$ (here fitted with a constant phase element, CPE [7, 32], characterized by an exponent of about 0.9). Both parameters exhibit no appreciable dependence on the potential (see Table S1), with an associated time constant of about $220 \mathrm{~ms}$, as calculated through the formula:

$$
\tau_{1}=R_{1} C_{1}
$$

On the other hand, Warburg diffusion element is given by [15]:

$$
Z_{W}=\frac{R_{d}}{\sqrt{j \omega \tau_{d}}} \tanh \left(\sqrt{j \omega \tau_{d}}\right)
$$

where $R_{\mathrm{d}}$ and $\tau_{\mathrm{d}}$ are the diffusion resistance and time constant, respectively. In accordance with the experimental data, a substantial decrement of both values is observed while reducing the external polarization resistance (as reported in Table S1), implying a significant dependency on the polarization condition. Finally, in this abiotic condition, the total internal resistance, given by the sum of $R_{\mathrm{s}}, R_{1}$ and $R_{\mathrm{d}}$, roughly equates the external load resistance for all the measured polarization points.

By colonizing the porous felt electrode with microbial biofilm, a new interface is created at the electrode/electrolyte boundary. To take into account this feature, the equivalent circuit used to fit the anode impedance was modified by adding the $R_{2}-C_{2}$ pair, accounting for the biofilm charge transfer resistance and double layer capacitance. This EEC, shown in Fig. 6b, refers to a normal turnover condition, and it is similar to that proposed for the first time by Jung et al. [19] to describe a mixed-community biofilm. By exploiting this circuit, the impedance spectra measured under different polarization conditions were fitted: the result of this procedure is reported in Fig. 3 and Fig. 4 superimposed to the experimental data and the corresponding fitting parameters are summarized in Tables 1 and 2. Analogously to the abiotic condition, $R_{\mathrm{S}}$ values were similar in all the measurements of both enrichments $(0.7$ $0.8 \Omega$, not reported in Tables 1 and 2), and not dependent on the polarization. Concerning the process at the interface between the electrolyte and electrode $\left(R_{1}-C_{1}\right.$ couple), this phenomenon was the fastest one, as evidenced by the time constants values, calculated through equation (1). In this case, CPE exponents lie in the range 0.9 - 1 . There was no dependence on anode polarization, since throughout the polarization profile the resistance and capacitance for this process did not change much and remained within the same range for each enrichment. To confirm this hypothesis, results from biotic (turnover), abiotic and nonturnover condition tests were compared (Fig. 7). The interfacial process was present in all the tested conditions, at the same frequency and with similar values of capacitance, ranging from 0.3 to $0.6 \mathrm{mF} / \mathrm{cm}^{2}$ (Tables 1,2 and S1) This large double layer capacitance originated from the high porosity of carbon felt material, that increases the surface area and the roughness of the electrode. The low frequency process is related to the biofilm. It is the slowest of all the charge transfer mechanisms, as evidenced by the time constant values $\tau_{2}$ reported in Tables 1 and 2 (calculated similarly to $\tau_{1}$ ). This process was dependent on the applied external resistance. The time constant was highest at open circuit condition and reduced until the maximum power point. Delving deeper into the capacitance (also in this case modeled 
through CPEs with exponents in the range $0.8-0.95$ ) and resistance values, revealed a variation of the resistance during polarization, while the capacitance remained more or less the same for a specific enrichment. Similarly to $\tau_{2}$, the change in resistance followed the trend of maximum power point: it decreased until the MPP and then increased again as the external load was beyond the MPP resistance. Very large values $\left(0.7-3.3 \mathrm{mF} / \mathrm{cm}^{2}\right)$ were obtained for the capacitance $C_{2}$ related to both bioanodes. These large biofilm double layer capacitance values were in accordance with those obtained in previous works [17, 19, 31] and can be attributed to the biofilm property of charge storage body or conductive matrix. Finally, the Warburg element represents the diffusion of the substrate (acetate) from the anolyte to the biofilm and of the products $\left(\mathrm{H}^{+}\right.$and $\left.\mathrm{HCO}_{3}{ }^{-}\right)$from the biofilm to the electrolyte. Consistent time constants, $\tau_{\mathrm{d}}$, were obtained for each enrichment under different conditions of polarization. Diffusion contribution should be observable at very low frequencies (in the $1-$ $100 \mathrm{mHz}$ range). However, its characteristic time constants are in the same range of $\tau_{2}$, thus limiting the visual detection of the diffusion in the Bode/Nyquist plots. This diffusion phenomenon was indeed masked by the large biofilm capacitance $C_{2}$, in accordance to what was observed by ter Heijne and coworkers for capacitance values of about $1 \mathrm{mF} / \mathrm{cm}^{2}$ [21]. It is worth noting that the aforementioned interpretation for the Warburg diffusion element is reinforced by the fact that this element was not present in the data fitted from experiments conducted in non-turnover conditions (Fig. 6c).

\subsubsection{Comparison of different enrichment methods}

The two mixed-community biofilms presented a different impedance behavior. As observed in Tables 1 and 2, FeC-enriched bioanodes showed slower processes and higher resistances values if compared to Gen-enriched ones. $\mathrm{FeC}$ enrichment is characterized by $\sim 4$ times slower $\tau_{\mathrm{d}}$ than general one, $14 \pm 2 \mathrm{~s}$ and $3.2 \pm 0.5 \mathrm{~s}$ respectively. This difference can be attributed to the fact that general-enriched bioanode exhibited a more dense/active microbial population (as discussed below, Section 3.6). This would lead to a higher consumption rate of substrate, resulting in the creation of a steeper diffusion gradient for acetate, and thus in faster $\tau_{\mathrm{d}}$ and lower $R_{\mathrm{d}}$ values.

Concerning the biofilm process, Gen-enriched bioanodes presented a $R_{2}$ value of about $76 \Omega$ at MPP, $\sim 3$ times lower than $\mathrm{FeC}$ ones (about $240 \Omega$ ). Also biofilm double layer capacitance $\left(C_{2}\right)$ was different between the two enrichments: $3.3-1.6 \mathrm{mF} / \mathrm{cm}^{2}$ for general bioanodes and $1.2-0.7 \mathrm{mF} / \mathrm{cm}^{2}$ for $\mathrm{FeC}$. These capacitances values are dependent on the structure of biofilm and how electroactive the biofilm is.

On the contrary, the values of Helmholtz layer capacitance $\left(C_{1}\right)$ were quite similar for both the enrichments, due to the fact that the anode electrode surface/geometry and the anolyte were the same. The interfacial resistance $R_{1}$ changed between the two enrichments: this variation can be associated with the fact that the two enrichments resulted in different microbial activity. It was evident from imaging analysis that FeC-enriched bioanode presented a higher percentage of dead/inactive bacteria covering the interface between the 
electrolyte and the electrode (Fig. 10). This could result in a generally higher resistance related to the interfacial process, as can be seen from the data reported in Tables 1 and 2.

\subsection{Cyclic voltammetry}

After polarization tests, a $1 \mathrm{k} \Omega$ external load was applied to all the devices. A stable current production was measured for 1 week, and then cyclic voltammetry measurements were performed. This technique is useful to study and characterize the electron transfer interactions between microorganisms or microbial biofilms and anode electrodes [33, 34]. We utilized CV to confirm the different electrochemical behaviors observed through EIS analysis.

The turnover voltammogram of Gen-enriched biofilms (reported in Fig. 8a) shows a sigmoidal catalytic shape, characteristic of acetate oxidation by microorganisms using conduction-based electron transfer [33, 35-37]. The first derivative of a sigmoidal function is a peak-shaped curve that can be used as a tool to identify the redox center contributing to current generation. As shown in the inset of Fig 8a, the putative electron transfer site of general enriched bioanode is centered at $-0.4 \mathrm{~V}$ vs $\mathrm{Ag} / \mathrm{AgCl}$. This potential is very close to the formal potential of outer membrane cytochromes of G. sulfurreducens, namely $-0.190 \mathrm{~V}$ vs standard hydrogen electrode (corresponding to -0.387 vs $\mathrm{Ag} / \mathrm{AgCl}$ ) [38].

The FeC-enriched bioanodes exhibit distinct turnover voltammograms (shown in Fig. 8b), revealing the presence of a redox system with a reduction peak at $-0.315 \mathrm{~V}$ and an oxidation peak at $-0.115 \mathrm{~V}$ vs $\mathrm{Ag} / \mathrm{AgCl}$ (midpoint potential $E^{\mathrm{f}}$ equal to $-0.215 \mathrm{~V}$ vs $\mathrm{Ag} / \mathrm{AgCl}$ ). This midpoint potential is consistent with that of phenazines, which serve as electron shuttles to alternate terminal acceptors and can be produced by a diverse range of bacteria [39]. The most studied phenazine is pyocyanin, it is secreted by Pseudomonas spp. and was previously detected on carbon electrodes in aqueous solution [40, 41]. This particular peaks-shaped curve indicated a non steady-state condition between diffusion and electron transfer, where the rate of diffusion does not match the rate of electron transfer. This results is in accordance with EIS data: FeC-enriched bioanodes exhibited a diffusion time constant larger than biofilm charge transfer one (see Table 2). On the contrary, Gen-enriched biofilms showed a faster diffusion process, allowing a steady state condition and therefore a sigmoidal shaped voltammogram.

Fig. 8 also shows the non-turnover response of bioanodes. In starving conditions the catalytic wave for both biofilms disappeared, demonstrating that the catalytic current was generated by microbial acetate oxidation.

\subsection{Electrochemical kinetics analysis: Butler-Volmer-Monod model}

In order to gain insights on the kinetics of the two different biofilms, polarization curves were fitted with Butler-Volmer-Monod (BVM) model [42]. This model describes the biochemical 
substrate oxidation (Monod general enzyme kinetics) and the electron transfer from the microorganism to the electrode (Butler-Volmer relationship). According to the BVM model, the current density can be expressed as:

$$
I=I_{\max } \frac{1-e^{-\frac{F}{R T} \eta}}{K_{1} e^{-\frac{(1-\alpha) F}{R T} \eta}+K_{2} e^{-\frac{F}{R T} \eta}+\left(\frac{K_{M}}{S}+1\right)}
$$

where $F$ is the Faraday constant, $R$ is the gas constant, $T$ is the absolute temperature, $\eta$ is the anodic overpotential, $K_{\mathrm{M}}$ is the substrate affinity constant or the so-called Michaelis-Menten constant, and $S$ is the substrate concentration. Fig. 9 reports the experimental data as well as the curves obtained by the BVM model, from which the following parameters can be extracted: $\alpha$ is the transfer coefficient, $I_{\max }$ is the maximum obtainable current density, and $K_{1}$ and $K_{2}$ are the kinetics parameters. $\alpha$ values equal to 0.50 and 0.78 were obtained for the Gen-enriched and FeC-enriched biofilms, respectively: these values are related to the ButlerVolmer electrochemical rate constant, and are usually in the range $0.40-0.80$ in the case of bioelectrochemical reactions $[43,44]$. Concerning the $K_{1}$ parameter, its value was found to be 0 for Gen-enriched bioanode. Such a value implies an extremely fast electron transfer mechanism, if compared to the biochemical reaction (substrate oxidation). In this condition, the BVM model behaves like the Nernst-Monod model [45]. On the contrary, $\mathrm{FeC}$ enrichment exhibits a $K_{1}$ value of 2.3: these results are in accordance with EIS and CV analyses, i.e. FeC-enriched biofilms are characterized by a less efficient electron transfer mechanism. Finally, $K_{2}$ was found to be larger than one for both enrichments (10.5 and 20.2 for $\mathrm{Gen}$ and $\mathrm{FeC}$ enrichment, respectively), as expected for microorganisms that degrade organic substrates to survive [42].

\subsection{Biofilms comparison through imaging}

Morphological characterization of microbial biofilm on the anode surface was performed using fluorescence microscopy after live/dead staining. This type of analysis is useful to elucidate biofilm distribution, density, heterogeneity and thickness [15].

As shown in Fig 10, in Gen enrichment as well as FeC enrichment the biofilm covers the carbon fibers of the felt; however, there is no formation of a denser mat covering the upper layer of the electrodic material (i.e. the layer exposed to the electrolyte). For this reason it was impossible to measure a real thickness of the biofilm to associate this characteristic to the behavior observed with EIS analysis [6].

Nonetheless, colonization of the entire 3D volume of the electrode was evaluated acquiring different $\mathrm{z}$-stacks starting from the upper layer of the material and moving towards the lower one (total felt thickness equal to $500 \mu \mathrm{m}$ ). The measurement indicated that Gen-enriched biofilm covers almost all the thickness of the carbon felt material (428 $\mu \mathrm{m} \pm 31$, average \pm standard deviation). On the contrary, the biofilm of ferric citrate enriched MFCs has a limited 
3D distribution through the electrode ( $325 \mu \mathrm{m} \pm 38$, average \pm standard deviation). This observation suggests that, despite the possible different ability and mechanisms of electron transfer that characterize the two mixed community, the Gen-enriched one can perform electron transfer to a wider distance along the electrode.

Another important feature observed is related to the balance between green colored microorganisms (live) and red ones (dead). In Gen-enriched bioanodes the ratio between live/dead microorganisms is $2.9 \pm 0.5$ (average \pm standard deviation) while, in the case of FeC-enriched bioanodes it decreases to $1.4 \pm 0.4$ (average \pm standard deviation). The better distribution through the anodic electrode in general enrichment together with the higher ratio of live/dead microorganisms contribute to the creation of a stepper diffusion gradient of acetate, resulting in a faster $\tau_{\mathrm{d}}$ and lower $R_{\mathrm{d}}$ values as aforementioned.

\section{Conclusion}

In this study, EIS analysis was performed to compare two mixed-community bioanodes, and to recognize the different processes occurring inside the anodic compartment of MFCs and their dependence on the diverse microbial communities.

The bioanode EIS measurements were performed in 3-electrode configuration as a function of the external resistance used during the polarization tests. A robust experimental set-up was developed to investigate and compare the two mixed-community bioanodes through impedance spectroscopy. Abiotic and non-turnover tests successfully helped to obtain an effective physical interpretation of the electrical processes occurring at biofilm/electrode level. The appropriate equivalent electrical circuit used to fit experimental data was composed by three time constants: a substrate/products diffusion process, a biofilm process and an electrode/electrolyte interfacial process.

Bioanodes impedance response, as function of different external loads, followed the trend of polarization curves, with lowest values at MPP for both enrichments. Moreover, the two biofilms showed a different impedance behavior. FeC-enriched bioanodes resulted in a less efficient electron transfer mechanisms, with diffusion limitations. More specifically, at MPP, Gen-enriched bioanodes exhibited a $\tau_{\mathrm{d}} \sim 4$ times faster, a biofilm resistance $\sim 3$ times lower and a biofilm double layer capacitance $\sim 2$ times higher than FeC-enriched ones. Also the interfacial phenomenon was dependent on the different microbial communities; in particular FeC-enriched biofilms showed higher resistance values than Gen-enriched one, indicating a more difficult charge transfer process at electrode/electrolyte interface.

These impedance results were confirmed by $\mathrm{CV}$, kinetics analysis and biofilm imaging. The classical sigmoidal voltammogram of direct electron transfer mechanism, with a midpoint potential of $-0.4 \mathrm{~V}$, was obtained only for Gen-enriched bioanodes. From the analysis of polarization curves fitted with Butler-Volmer-Monod model, this biofilms exhibited an extremely fast electron transfer kinetic. Finally, a better coverage of carbon fibers and a higher percentage of live and active microorganisms resulted from imaging analysis. 


\section{Acknowledgements}

The authors would like to thank all the members of the BioEnergy research group at IIT@Polito. 


\section{Tables}

Table 1. Parameters extracted from fitting of the impedance spectra recorded during polarization test for the Gen-enriched bioanode shown in Fig. 3a. For each parameter, the maximum variation observed between the two MFCs was $7 \%$.

\begin{tabular}{cccccccccc}
\hline $\begin{array}{c}\text { Polarization } \\
\text { resistance }(\boldsymbol{\Omega})\end{array}$ & $\begin{array}{c}\boldsymbol{R}_{\mathbf{1}} \\
(\boldsymbol{\Omega})\end{array}$ & $\begin{array}{c}\boldsymbol{C}_{\mathbf{1}} \\
(\mathbf{m F})\end{array}$ & $\begin{array}{c}\boldsymbol{\tau}_{\mathbf{1}} \\
(\mathbf{s})\end{array}$ & $\begin{array}{c}\boldsymbol{R}_{\mathbf{2}} \\
(\boldsymbol{\Omega})\end{array}$ & $\begin{array}{c}\boldsymbol{C}_{\mathbf{2}} \\
(\mathbf{m F})\end{array}$ & $\begin{array}{c}\boldsymbol{\tau}_{2} \\
(\mathbf{s})\end{array}$ & $\begin{array}{c}\boldsymbol{R}_{\mathbf{d}} \\
(\boldsymbol{\Omega})\end{array}$ & $\begin{array}{c}\boldsymbol{\tau}_{d} \\
(\mathbf{s})\end{array}$ & $\begin{array}{c}\chi^{2} \\
\left(\cdot \mathbf{1 0}^{-5}\right)\end{array}$ \\
\hline OC & 16.2 & 18.7 & 0.30 & 2861.0 & 128.7 & 368.34 & 8.1 & 3.88 & 6.03 \\
8200 & 16.5 & 20.4 & 0.34 & 357.1 & 61.9 & 22.10 & 7.3 & 3.26 & 14.12 \\
4700 & 13.9 & 20.2 & 0.28 & 177.0 & 62.2 & 11.01 & 7.1 & 3.22 & 2.93 \\
2200 & 12.8 & 20.0 & 0.26 & 80.5 & 63.2 & 5.09 & 7.0 & 2.99 & 5.51 \\
1000 & 11.0 & 20.6 & 0.23 & 75.7 & 63.0 & 4.76 & 6.8 & 2.77 & 5.90 \\
330 & 9.9 & 21.3 & 0.21 & 100.2 & 98.8 & 9.88 & 7.9 & 3.39 & 3.70 \\
\hline
\end{tabular}

Table 2. Parameters extracted from fitting of the impedance spectra recorded during polarization test for the $\mathrm{FeC}$-enriched bioanode shown in Fig. 3b. For each parameter, the maximum variation observed between the two MFCs was $5 \%$.

\begin{tabular}{cccccccccc}
\hline $\begin{array}{c}\text { Polarization } \\
\text { resistance }(\boldsymbol{\Omega})\end{array}$ & $\begin{array}{c}\boldsymbol{R}_{\mathbf{1}} \\
(\boldsymbol{\Omega})\end{array}$ & $\begin{array}{c}\boldsymbol{C}_{\mathbf{1}} \\
(\mathbf{m F})\end{array}$ & $\begin{array}{c}\boldsymbol{\tau}_{\boldsymbol{1}} \\
(\mathbf{s})\end{array}$ & $\begin{array}{c}\boldsymbol{R}_{\mathbf{2}} \\
(\boldsymbol{\Omega})\end{array}$ & $\begin{array}{c}\boldsymbol{C}_{\mathbf{2}} \\
(\mathbf{m F})\end{array}$ & $\begin{array}{c}\boldsymbol{\tau}_{2} \\
(\mathbf{s})\end{array}$ & $\begin{array}{c}\boldsymbol{R}_{\mathbf{d}} \\
(\boldsymbol{\Omega})\end{array}$ & $\begin{array}{c}\boldsymbol{\tau}_{d} \\
(\mathbf{s})\end{array}$ & $\begin{array}{c}\chi^{2} \\
\left(\cdot \mathbf{1 0}^{-5}\right)\end{array}$ \\
\hline OC & 46.3 & 26.1 & 1.21 & 3106.2 & 36.5 & 113.45 & 16.1 & 16.36 & 5.86 \\
8200 & 40.9 & 27.4 & 1.12 & 500.9 & 28.4 & 14.25 & 15.5 & 15.95 & 8.88 \\
4700 & 42.4 & 26.3 & 1.11 & 335.8 & 36.2 & 12.14 & 15.2 & 14.75 & 5.87 \\
2200 & 45.9 & 25.0 & 1.15 & 295.0 & 46.4 & 13.67 & 14.4 & 12.56 & 2.66 \\
1000 & 40.0 & 25.9 & 1.03 & 240.5 & 44.3 & 10.67 & 13.3 & 12.16 & 4.84 \\
680 & 41.2 & 23.6 & 0.97 & 317.3 & 39.3 & 12.47 & 15.0 & 14.23 & 4.13 \\
\hline
\end{tabular}




\section{Figure captions}

Fig. 1. MFCs acclimation phase: anodic potential (left axis, closed symbols) and current density production (right axis, open symbols) as a function of the time. The maximum variation observed at each point for a pair of MFCs with the same enrichment was $7 \%$.

Fig. 2. a) Anode potential (left axis, closed symbols) and power density (right axis, open symbols) as a function of current density. b) Bioanodes power density as a function of anode potential. Each point is the average of data obtained from two MFCs inoculated with the same enrichment.

Fig. 3. Typical impedance response (Nyquist plot) of the two different bioanodes as a function of the external polarization resistance: a) General enrichment; b) $\mathrm{Fe}$ citrate enrichment. The points are experimental data, while the lines are related to the fitting procedure performed through the use of the EEC shown in Fig. 6b. The open symbols refer to measurements acquired at 3000, 300, 30, 3, 0.3, 0.03 and $0.003 \mathrm{~Hz}$.

Fig. 4. Typical impedance response (Bode plots) of the two different bioanodes as a function of the external polarization resistance: a) General enrichment; b) Fe citrate enrichment. The points are experimental data, while the lines are related to the fitting procedure performed through the use of the EEC shown in Fig. $6 b$.

Fig. 5. Impedance response (Bode plots) of abiotic anode as a function of external resistance. The points are experimental data, while the lines are related to the fitting procedure performed through the use of the EEC shown in Fig. 6 a.

Fig. 6. Equivalent electrical circuits used for the fit of EIS data: a) abiotic anode; b) turnover bioanode; c) non-turnover bioanode

Fig. 7. Impedance spectra (Bode plots) of Gen-enriched bioanode in turnover and nonturnover conditions and of abiotic anode measured at $1 \mathrm{k} \Omega$. The black arrow indicates the interfacial process.

Fig. 8. Cyclic voltammograms of the different bioanodes recorded at the scan rate of $1 \mathrm{mV} / \mathrm{s}$ in turnover and non-turnover conditions. (a) General-enriched biofilm. The inset shows the first derivative of the turnover $\mathrm{CV}$, where $E^{\mathrm{f}}$ indicates the putative electron transfer site centered at -0.4 V. (b) FeC-enriched biofilm. $E^{\mathrm{f}}$ centered at $-0.215 \mathrm{~V}$ indicates the arithmetic average of the oxidation and reduction peaks.

Fig. 9. Polarization curves of the two different bioanodes and relative fitting using the ButlerVolmer-Monod model.

Fig. 10. Biofilm fluorescence imaging of live/dead staining. (a) Gen-enriched biofilm, Max Intensity Projection (MaxIP) merge of green (live organisms) and red (dead organisms) channels. (b) Automated spot count relative to green channel. (c) Automated spot count relative to red channel. (d) FeC-enriched biofilm, MaxIP merge of green and red channels. (e) Automated spot count relative to green channel. (f) Automated spot count relative to red channel. 
[1] M.E. Orazem, B. Tribollet, Electrochemical Impedance Spectroscopy, Wiley, Hoboken, New Jersey, 2008.

[2] M.A. Danzer, E.P. Hofer, Analysis of the electrochemical behaviour of polymer electrolyte fuel cells using simple impedance models, J. Power Sources 190 (2009) 25.

[3] A. Sacco, F. Bella, S. De La Pierre, M. Castellino, S. Bianco, R. Bongiovanni, C.F. Pirri, Electrodes/Electrolyte Interfaces in the Presence of a Surface-Modified Photopolymer Electrolyte: Application in Dye-Sensitized Solar Cells, ChemPhysChem 16 (2015) 960.

[4] A. Mani, C. Huisman, A. Goossens, J. Schoonman, Mott-Schottky Analysis and Impedance Spectroscopy of $\mathrm{TiO}_{2} / 6 \mathrm{~T}$ and $\mathrm{ZnO} / 6 \mathrm{~T}$ devices, J. Phys. Chem. B 112 (2008) 10086.

[5] S. Hernández, M. Tortello, A. Sacco, M. Quaglio, T. Meyer, S. Bianco, G. Saracco, C.F. Pirri, E. Tresso, New Transparent Laser-Drilled Fluorine-doped Tin Oxide covered Quartz Electrodes for Photo-Electrochemical Water Splitting, Electrochim. Acta 131 (2014) 184.

[6] X. Dominguez-Benetton, S. Sevda, K. Vanbroekhoven, D. Pant, The accurate use of impedance analysis for the study of microbial electrochemical systems, Chem. Soc. Rev. 41 (2012) 7228.

[7] R.A. Yoho, S.C. Popat, F. Fabregat-Santiago, S. Giménez, A.t. Heijne, C.I. Torres, H. Beyenal, J. Babauta, Electrochemical Impedance Spectroscopy as a Powerful Analytical Tool for the Study of Microbial Electrochemical Cells, Biofilms in Bioelectrochemical Systems, John Wiley \& Sons, 2015 , pp. 249.

[8] B.E. Logan, Exoelectrogenic bacteria that power microbial fuel cells, Nat. Rev. Micro. 7 (2009) 375.

[9] K. Rabaey, W. Verstraete, Microbial fuel cells: novel biotechnology for energy generation, Trends Biotechnol. 23 (2005) 291.

[10] L.E. Doyle, E. Marsili, Methods for enrichment of novel electrochemically-active microorganisms, Bioresour. Technol. 195 (2015) 273.

[11] Z. He, N. Wagner, S.D. Minteer, L.T. Angenent, An Upflow Microbial Fuel Cell with an Interior Cathode: Assessment of the Internal Resistance by Impedance Spectroscopy, Environ. Sci. Technol. 40 (2006) 5212.

[12] D. Aaron, C. Tsouris, C.Y. Hamilton, A.P. Borole, Assessment of the Effects of Flow Rate and Ionic Strength on the Performance of an Air-Cathode Microbial Fuel Cell Using Electrochemical Impedance Spectroscopy, Energies 3 (2010) 592.

[13] B. Wei, J.C. Tokash, F. Zhang, Y. Kim, B.E. Logan, Electrochemical analysis of separators used in single-chamber, air-cathode microbial fuel cells, Electrochim. Acta 89 (2013) 45.

[14] X. Wang, Y. Feng, N. Ren, H. Wang, H. Lee, N. Li, Q. Zhao, Accelerated start-up of twochambered microbial fuel cells: Effect of anodic positive poised potential, Electrochim. Acta 54 (2009) 1109.

[15] N. Sekar, R.P. Ramasamy, Electrochemical Impedance Spectroscopy for Microbial Fuel Cell Characterization, J. Microbial Biochem. Technol. S6 (2013) 004.

[16] A.K. Manohar, O. Bretschger, K.H. Nealson, F. Mansfeld, The use of electrochemical impedance spectroscopy (EIS) in the evaluation of the electrochemical properties of a microbial fuel cell, Bioelectrochemistry 72 (2008) 149.

[17] R.P. Ramasamy, Z. Ren, M.M. Mench, J.M. Regan, Impact of initial biofilm growth on the anode impedance of microbial fuel cells, Biotechnol. Bioeng. 101 (2008) 101.

[18] S. Jung, Impedance Analysis of Geobacter sulfurreducens PCA, Shewanella oneidensis MR-1, and their Coculture in Bioeletrochemical Systems, Int. J. Electrochem. Sci. 7 (2012) 11091

[19] S. Jung, M.M. Mench, J.M. Regan, Impedance Characteristics and Polarization Behavior of a Microbial Fuel Cell in Response to Short-Term Changes in Medium pH, Environ. Sci. Technol. 45 (2011) 9069.

[20] R. Karthikeyan, B. Wang, J. Xuan, J.W.C. Wong, P.K.H. Lee, M.K.H. Leung, Interfacial electron transfer and bioelectrocatalysis of carbonized plant material as effective anode of microbial fuel cell, Electrochim. Acta 157 (2015) 314. 
[21] A. ter Heijne, O. Schaetzle, S. Gimenez, L. Navarro, B. Hamelers, F. Fabregat-Santiago, Analysis of bio-anode performance through electrochemical impedance spectroscopy, Bioelectrochemistry 106, Part A (2015) 64.

[22] R. Rousseau, M. Rimboud, M.-L. Délia, A. Bergel, R. Basséguy, Electrochemical characterization of microbial bioanodes formed on a collector/electrode system in a highly saline electrolyte, Bioelectrochemistry 106, Part A (2015) 97.

[23] S. Sevda, K. Chayambuka, T.R. Sreekrishnan, D. Pant, X. Dominguez-Benetton, A comprehensive impedance journey to continuous microbial fuel cells, Bioelectrochemistry 106, Part A (2015) 159.

[24] V. Margaria, T. Tommasi, S. Pentassuglia, V. Agostino, A. Sacco, C. Armato, A. Chiodoni, T. Schilirò, M. Quaglio, Effects of $\mathrm{pH}$ variations on anodic marine consortia in a dual chamber microbial fuel cell, Int. J. Hydrogen Energy, in press, DOI: 10.1016/j.ijhydene.2016.07.250.

[25] Y. Liu, D. Deng, X. Lan, A Highly Efficient Mixed-culture Biofilm as Anodic Catalyst and Insights into Its Enhancement through Electrochemistry by Comparison with G. sulfurreducens, Electrochim. Acta 155 (2015) 327.

[26] E. Marsili, J.B. Rollefson, D.B. Baron, R.M. Hozalski, D.R. Bond, Microbial Biofilm Voltammetry: Direct Electrochemical Characterization of Catalytic Electrode-Attached Biofilms, Appl. Environ. Microbiol. 74 (2008) 7329.

[27] K. Sathish-Kumar, O. Solorza-Feria, J. Tapia-Ramírez, N. Rinderkenecht-Seijas, H.M. PoggiVaraldo, Electrochemical and chemical enrichment methods of a sodic-saline inoculum for microbial fuel cells, Int. J. Hydrogen Energy 38 (2013) 12600.

[28] Y. Hong, D.F. Call, C.M. Werner, B.E. Logan, Adaptation to high current using low external resistances eliminates power overshoot in microbial fuel cells, Biosens. Bioelectron. 28 (2011) 71.

[29] K.P. Katuri, K. Scott, I.M. Head, C. Picioreanu, T.P. Curtis, Microbial fuel cells meet with external resistance, Bioresour. Technol. 102 (2011) 2758.

[30] L. Zhang, X. Zhu, J. Li, Q. Liao, D. Ye, Biofilm formation and electricity generation of a microbial fuel cell started up under different external resistances, J. Power Sources 196 (2011) 6029.

[31] D. Sanchez-Herrera, D. Pacheco-Catalan, R. Valdez-Ojeda, B. Canto-Canche, X. DominguezBenetton, J. Domínguez-Maldonado, L. Alzate-Gaviria, Characterization of anode and anolyte community growth and the impact of impedance in a microbial fuel cell, BMC Biotechnol. 14 (2014) 102.

[32] D. Hidalgo, A. Sacco, S. Hernández, T. Tommasi, Electrochemical and impedance characterization of Microbial Fuel Cells based on 2D and 3D anodic electrodes working with seawater microorganisms under continuous operation, Bioresour. Technol. 195 (2015) 139.

[33] K. Fricke, F. Harnisch, U. Schroder, On the use of cyclic voltammetry for the study of anodic electron transfer in microbial fuel cells, Energy Environ. Sci. 1 (2008) 144.

[34] E. LaBelle, D.R. Bond, Cyclic voltammetry of electrode-attached bacteria, in: P. Lens (Ed.) Bioelectrochemical Systems: from extracellular electron transfer to biotechnological application, Wageningen University, The Netherlands, 2009.

[35] L. Peng, X.-T. Zhang, J. Yin, S.-Y. Xu, Y. Zhang, D.-T. Xie, Z.-L. Li, Geobacter sulfurreducens adapts to low electrode potential for extracellular electron transfer, Electrochim. Acta 191 (2016) 743.

[36] C. Li, K.L. Lesnik, Y. Fan, H. Liu, Redox Conductivity of Current-Producing Mixed Species Biofilms, PLoS ONE 11 (2016) e0155247.

[37] B. Virdis, D. Millo, B.C. Donose, Y. Lu, D.J. Batstone, J.O. Kromer, Analysis of electron transfer dynamics in mixed community electroactive microbial biofilms, RSC Adv. 6 (2016) 3650 .

[38] T.S. Magnuson, N. Isoyama, A.L. Hodges-Myerson, G. Davidson, M.J. Maroney, G.G. Geesey, D.R. Lovley, Isolation, characterization and gene sequence analysis of a membrane-associated 89 kDa Fe(III) reducing cytochrome c from Geobacter sulfurreducens, Biochem. J. 359 (2001) 147.

[39] L.S. Pierson, E.A. Pierson, Metabolism and function of phenazines in bacteria: impacts on the behavior of bacteria in the environment and biotechnological processes, Appl. Microbiol. Biotechnol. 86 (2010) 1659. 
[40] T. Seviour, L.E. Doyle, S.J.L. Lauw, J. Hinks, S.A. Rice, V.J. Nesatyy, R.D. Webster, S. Kjelleberg, E. Marsili, Voltammetric profiling of redox-active metabolites expressed by Pseudomonas aeruginosa for diagnostic purposes, Chem. Commun. 51 (2015) 3789.

[41] D. Sharp, P. Gladstone, R.B. Smith, S. Forsythe, J. Davis, Approaching intelligent infection diagnostics: Carbon fibre sensor for electrochemical pyocyanin detection, Bioelectrochemistry 77 (2010) 114.

[42] H.V.M. Hamelers, A. ter Heijne, N. Stein, R.A. Rozendal, C.J.N. Buisman, Butler-VolmerMonod model for describing bio-anode polarization curves, Bioresour. Technol. 102 (2011) 381.

[43] J. Hong, H. Ghourchian, A.A. Moosavi-Movahedi, Direct electron transfer of redox proteins on a Nafion-cysteine modified gold electrode, Electrochem. Commun. 8 (2006) 1572.

[44] S.-F. Wang, T. Chen, Z.-L. Zhang, X.-C. Shen, Z.-X. Lu, D.-W. Pang, K.-Y. Wong, Direct Electrochemistry and Electrocatalysis of Heme Proteins Entrapped in Agarose Hydrogel Films in Room-Temperature Ionic Liquids, Langmuir 21 (2005) 9260.

[45] C.I. Torres, A.K. Marcus, P. Parameswaran, B.E. Rittmann, Kinetic Experiments for Evaluating the Nernst-Monod Model for Anode-Respiring Bacteria (ARB) in a Biofilm Anode, Environ. Sci. Technol. 42 (2008) 6593. 
Click here to download high resolution image
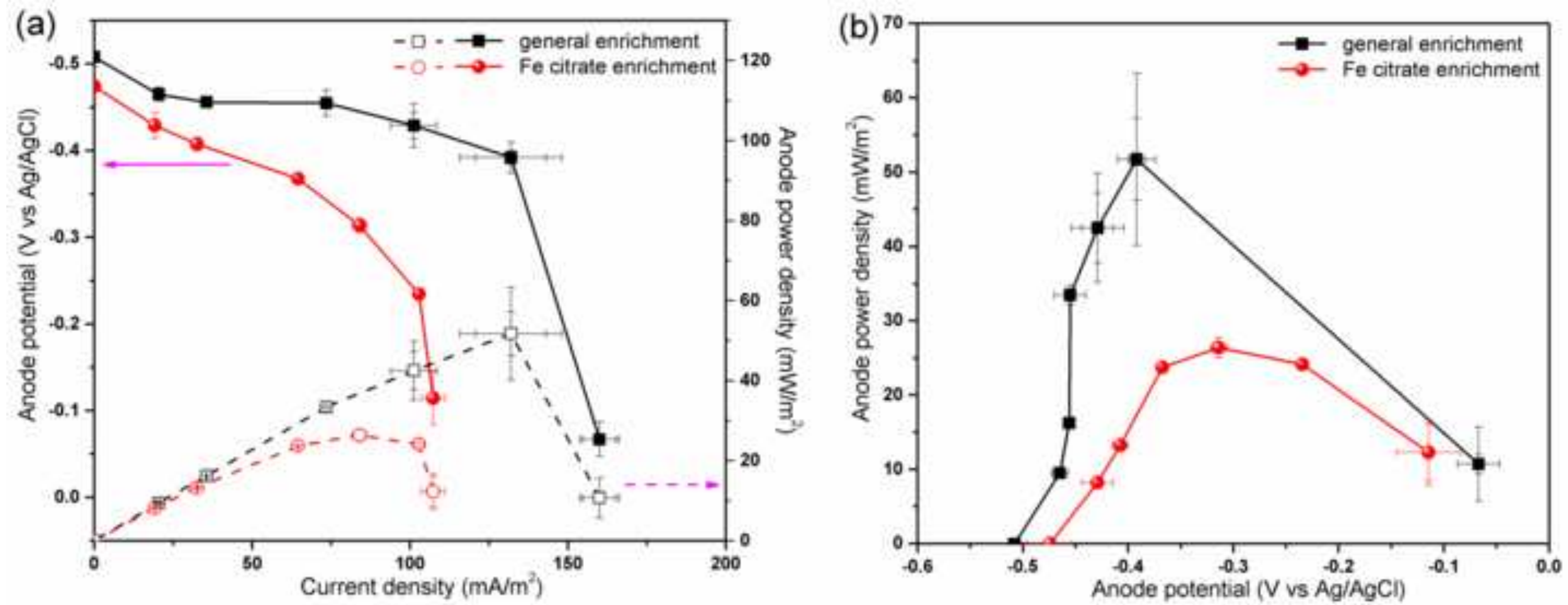
Click here to download high resolution image

(a)

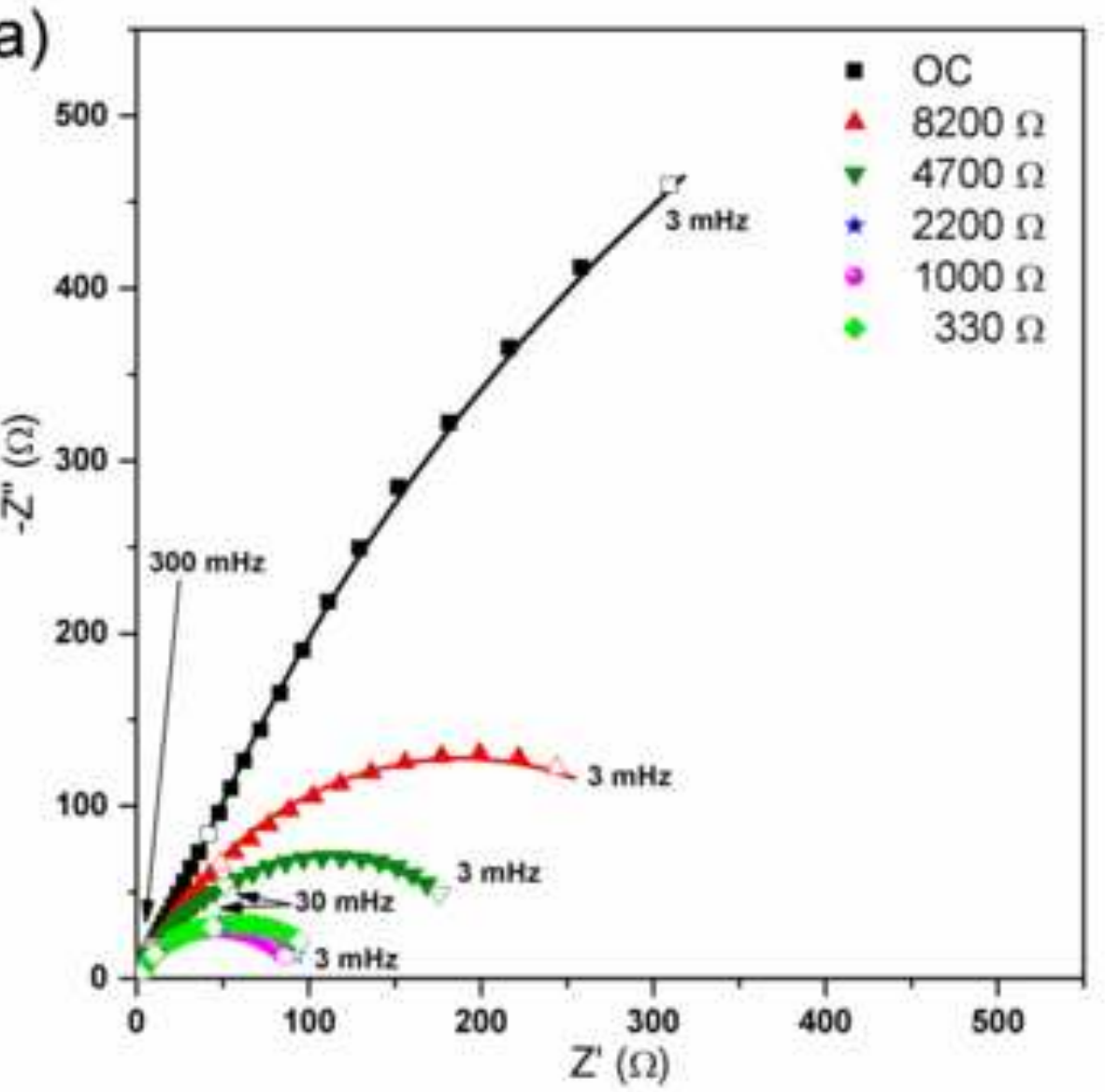

(b)

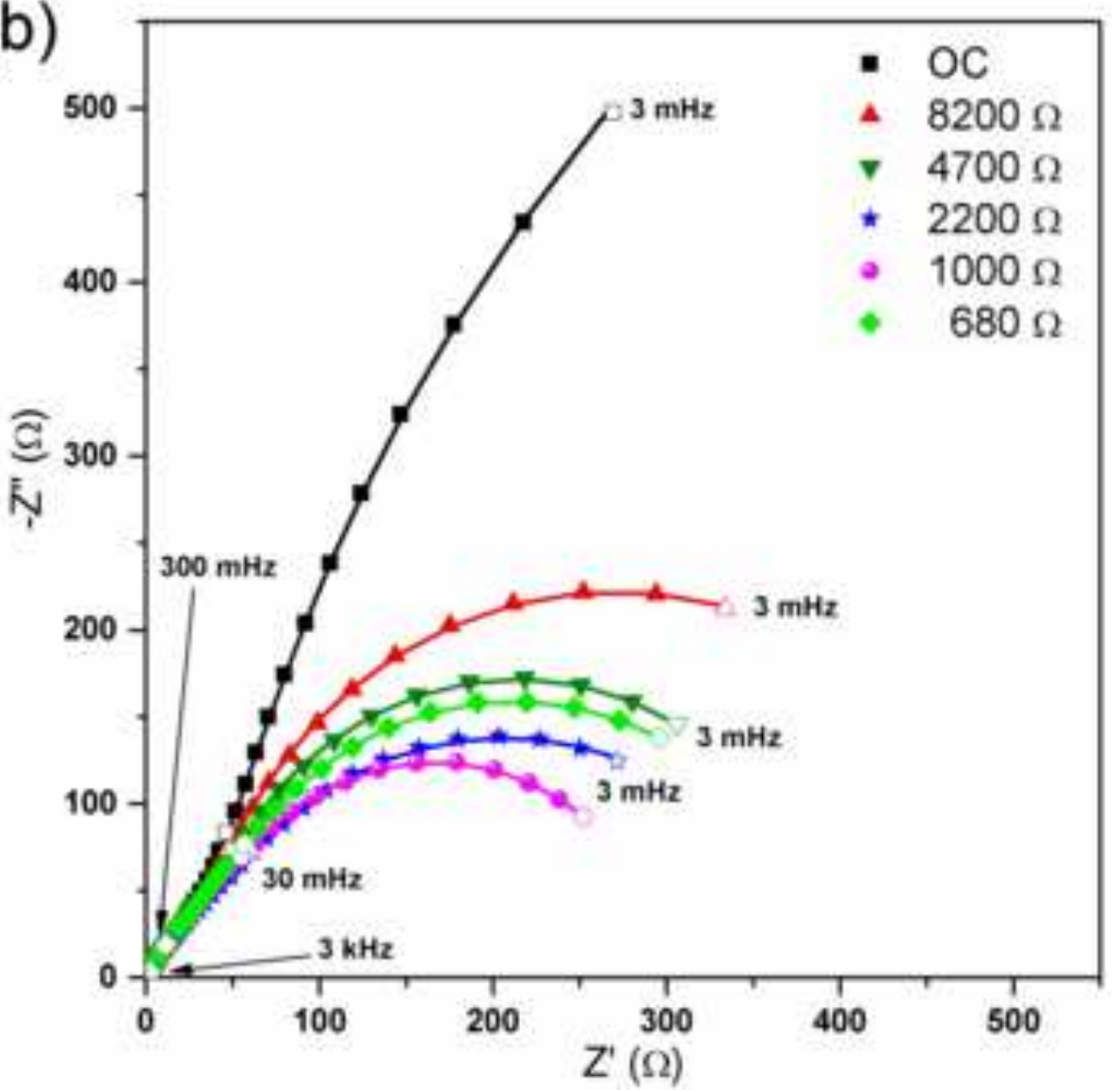


Click here to download high resolution image
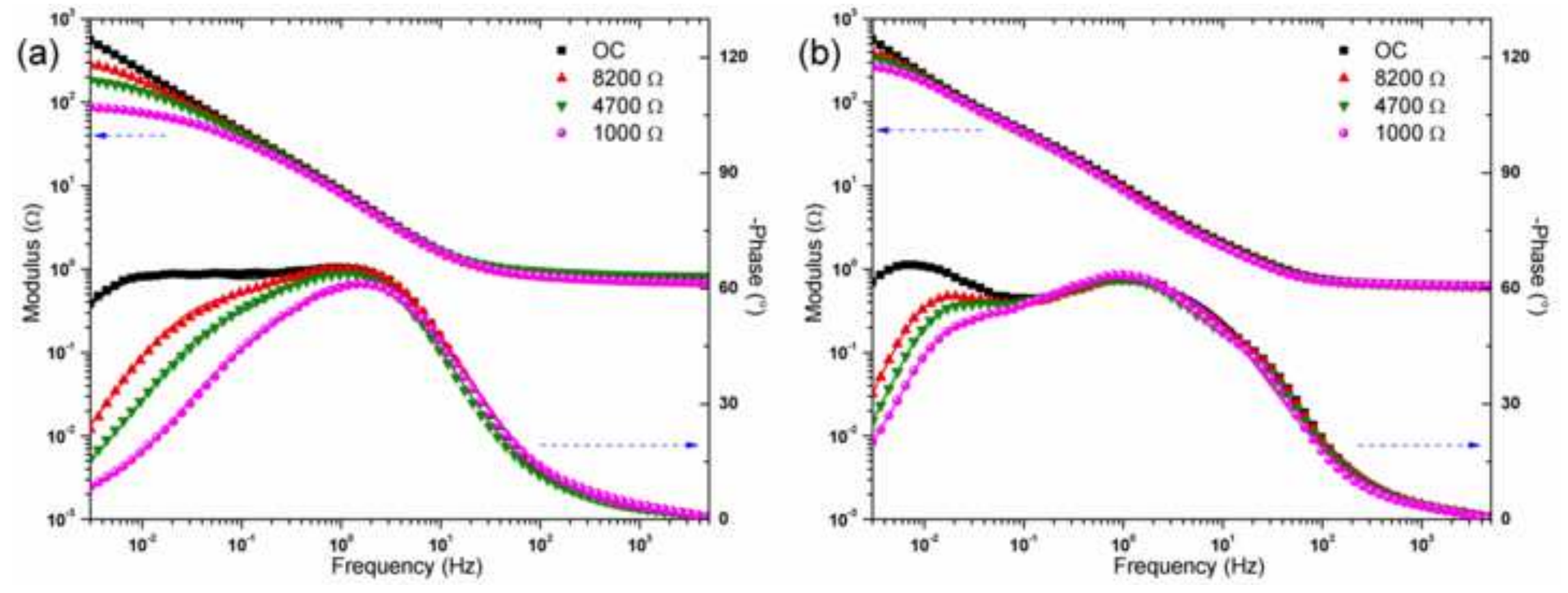

d 
Click here to download high resolution image

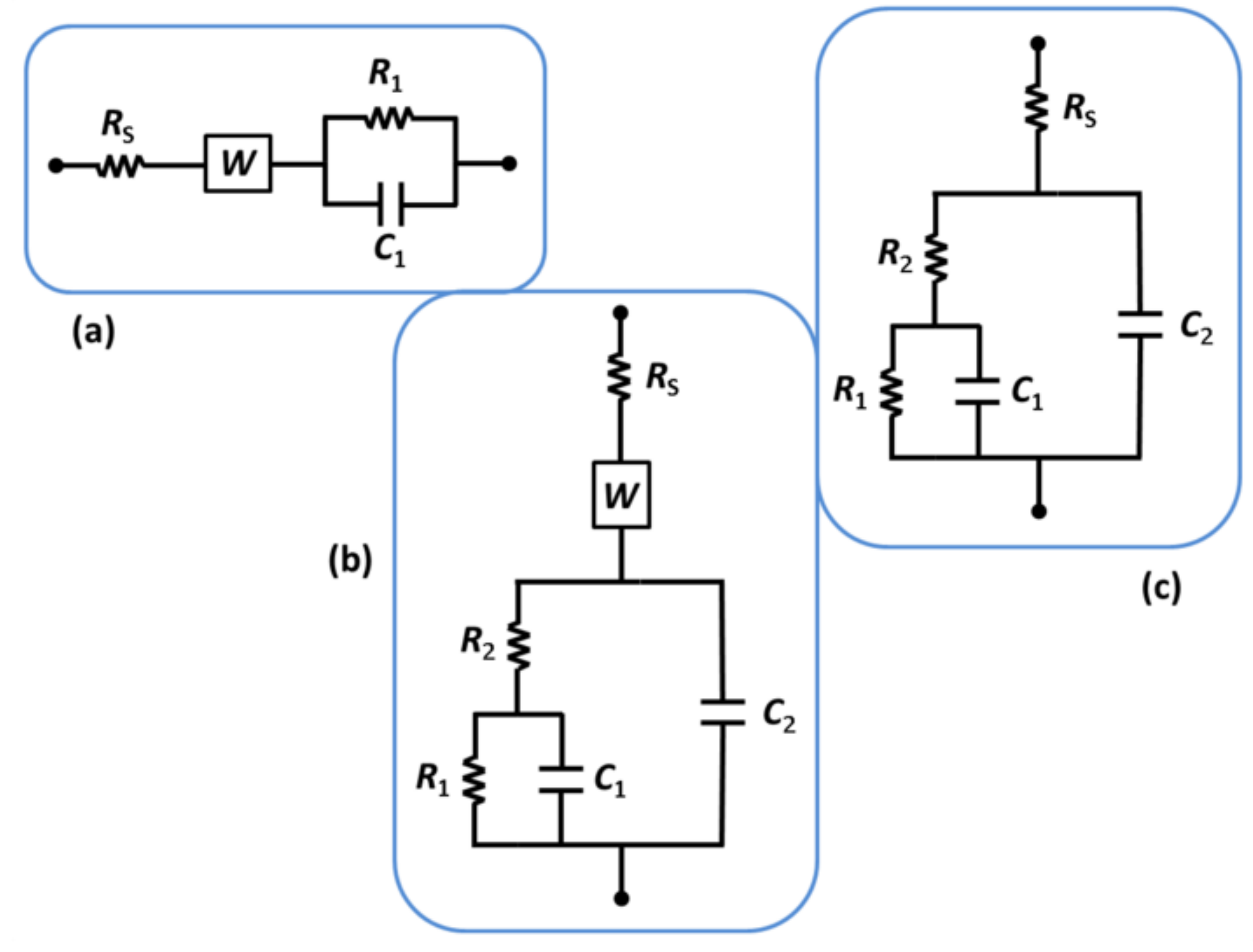


Click here to download high resolution image

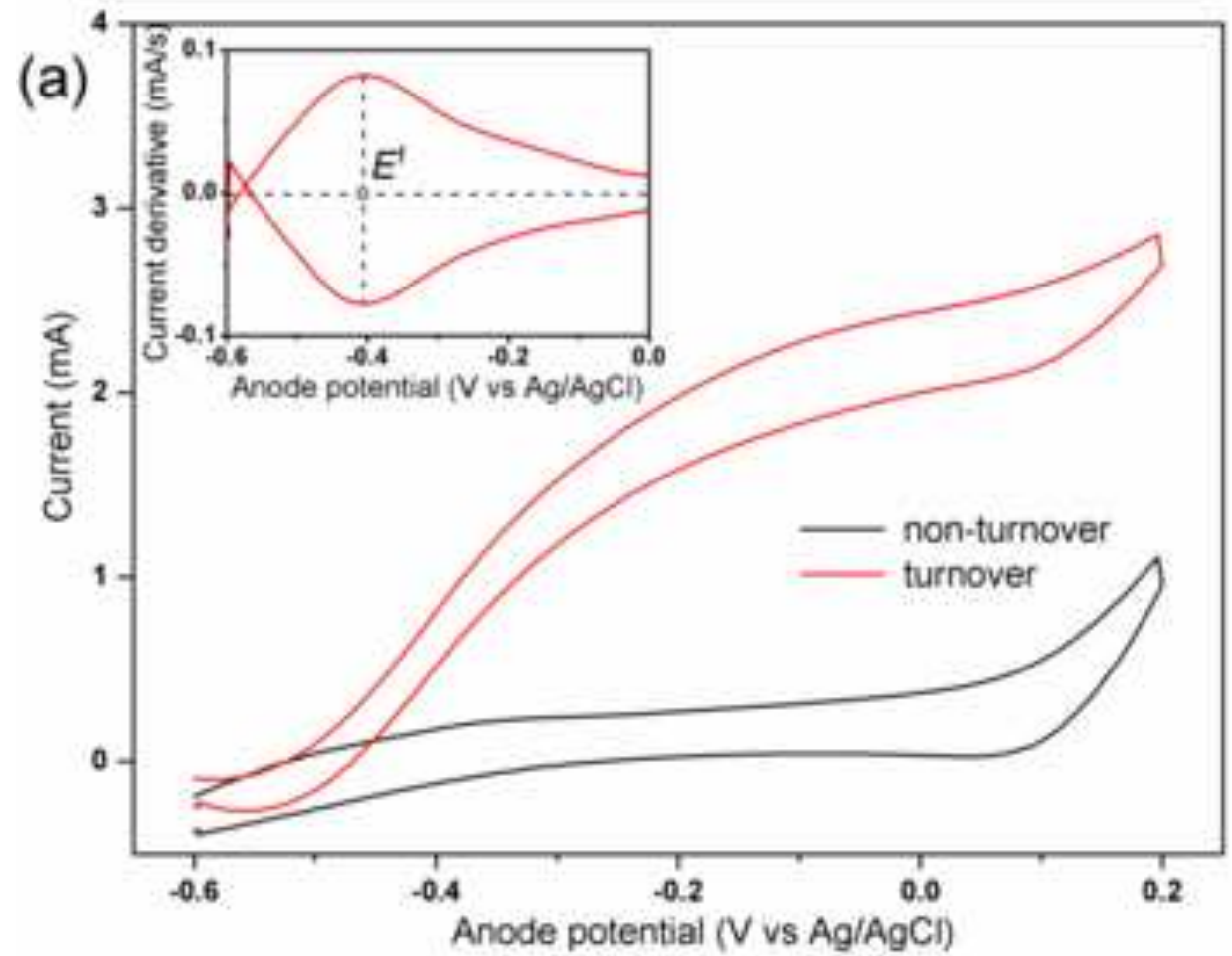

(a)

Anode potential ( $\mathrm{V}$ vs $\mathrm{Ag} / \mathrm{AgCl}$ )

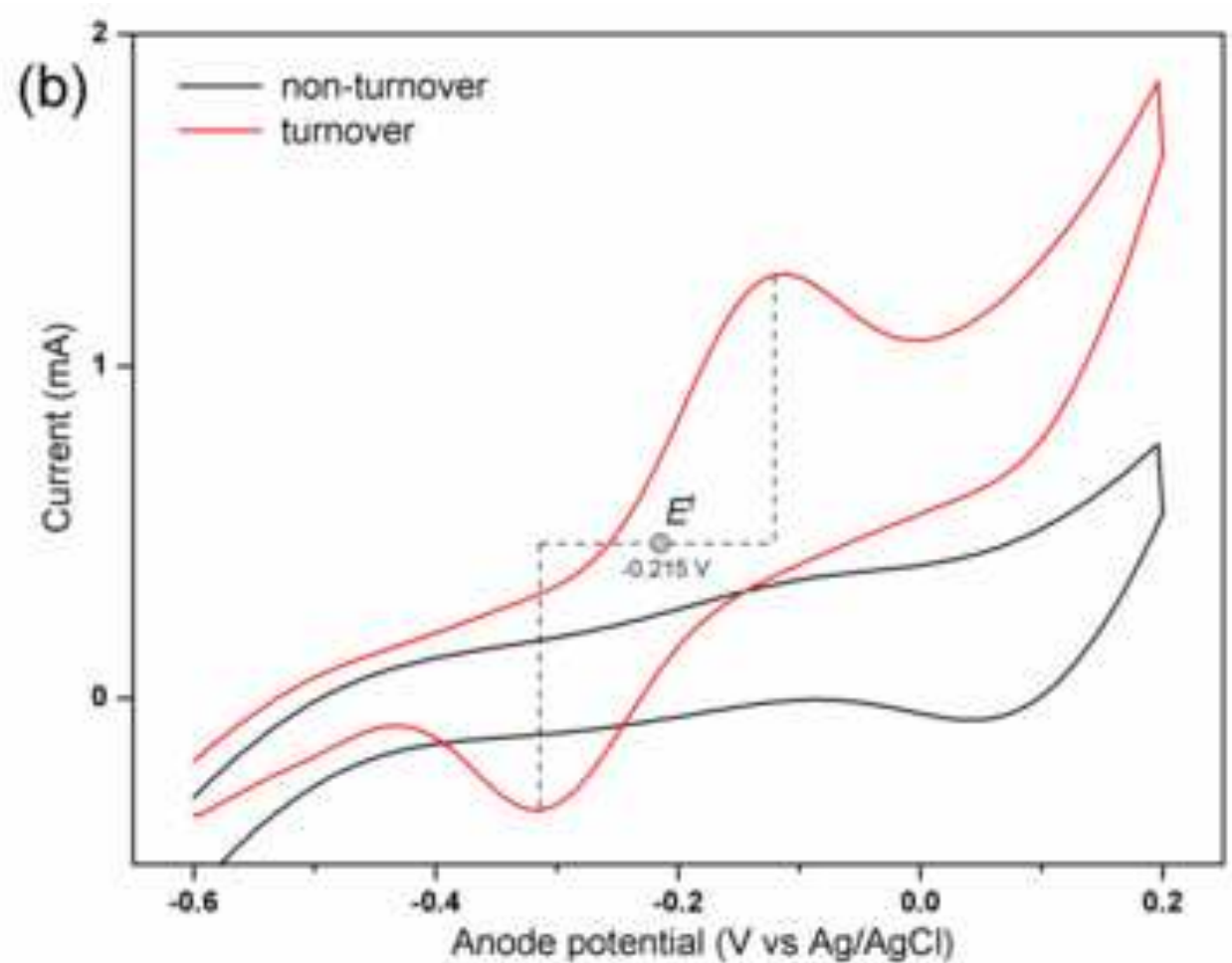




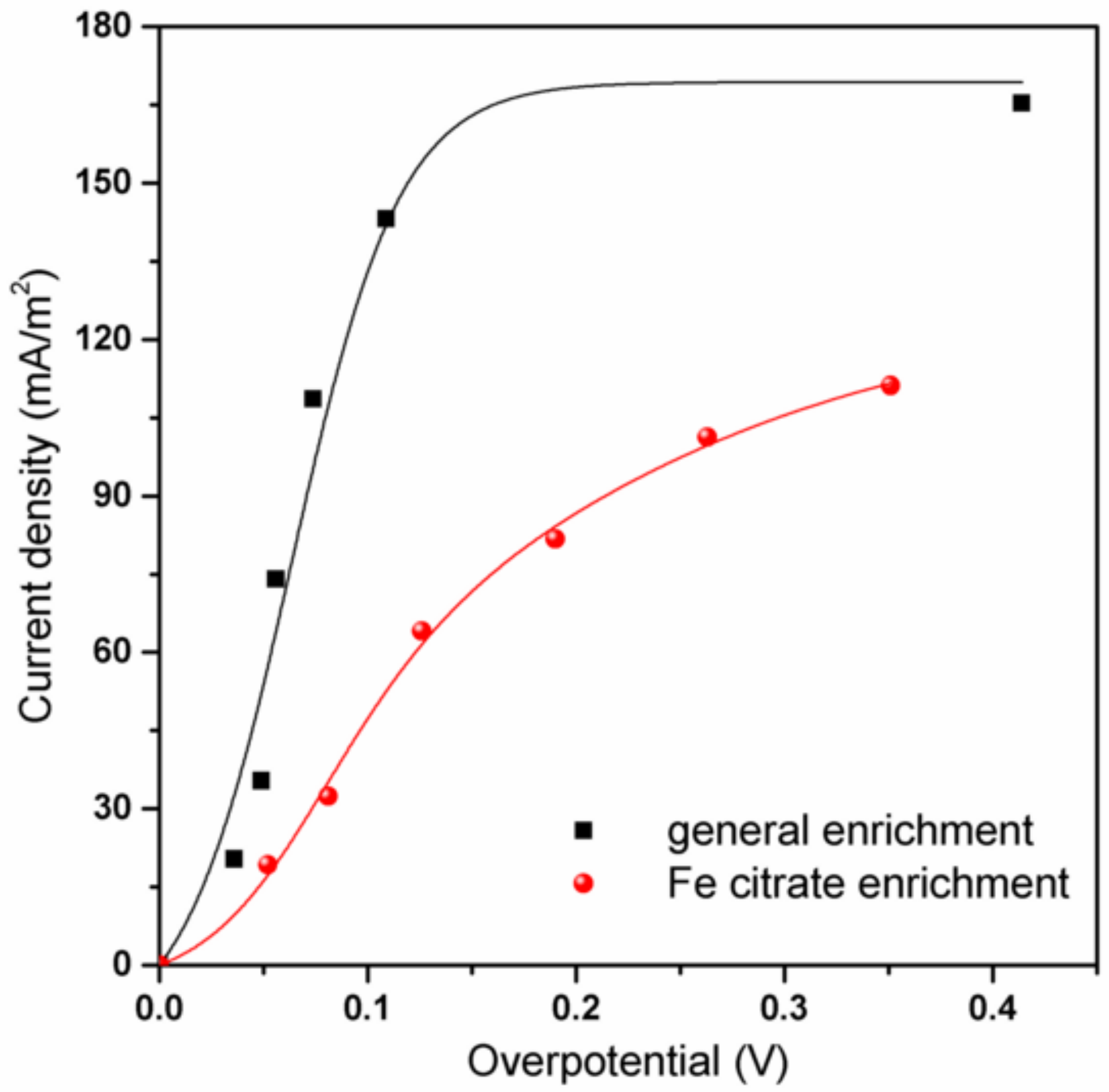




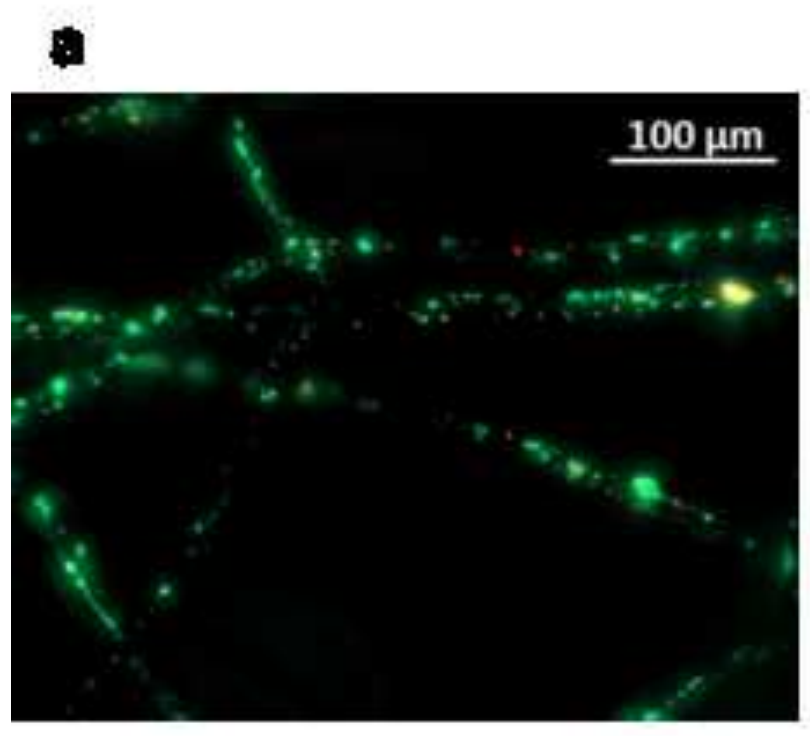

b

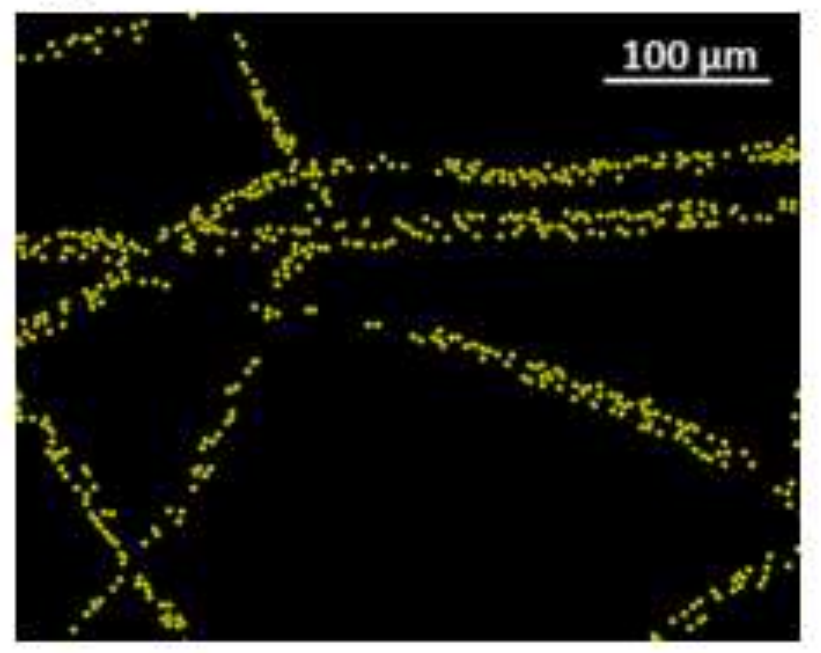

e
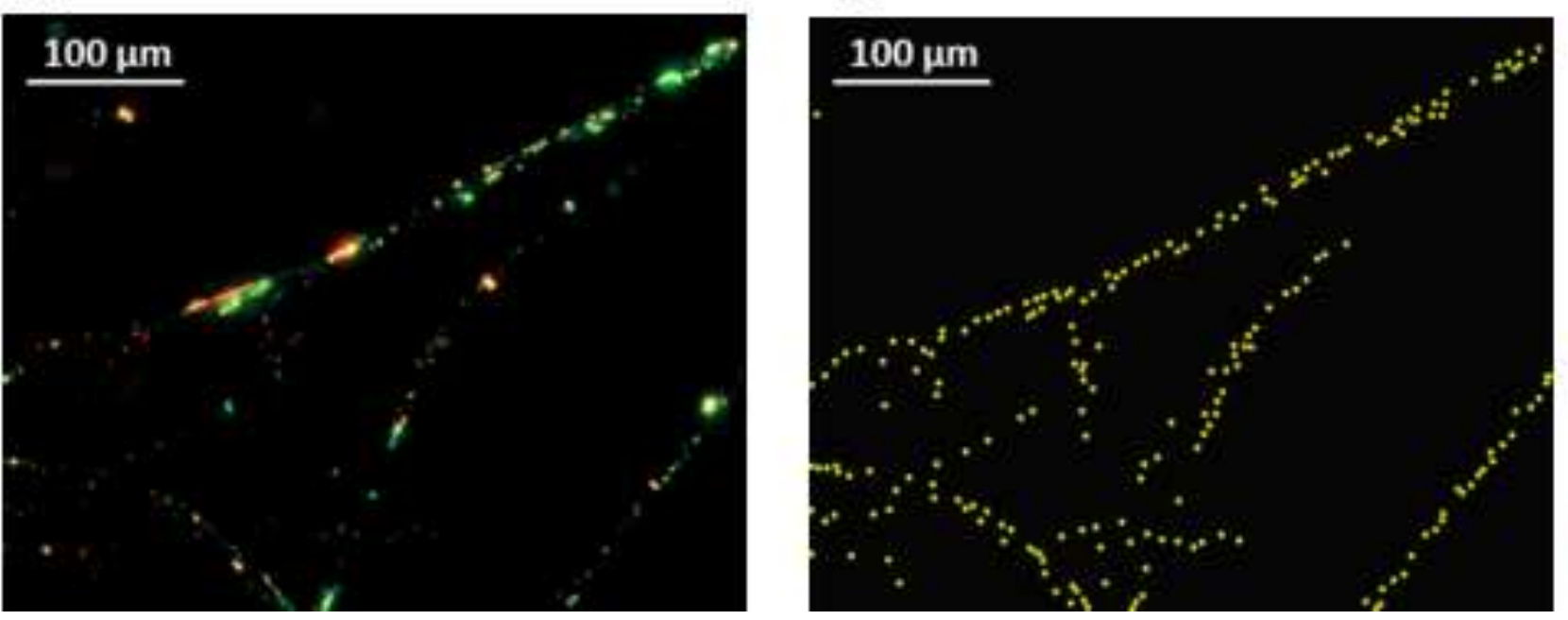

c

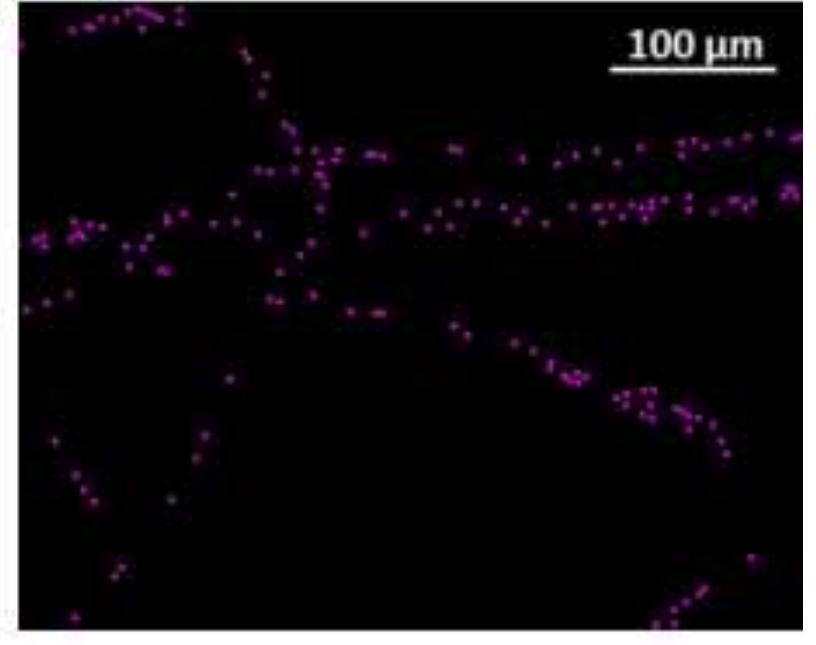

$f$

$100 \mu \mathrm{m}$

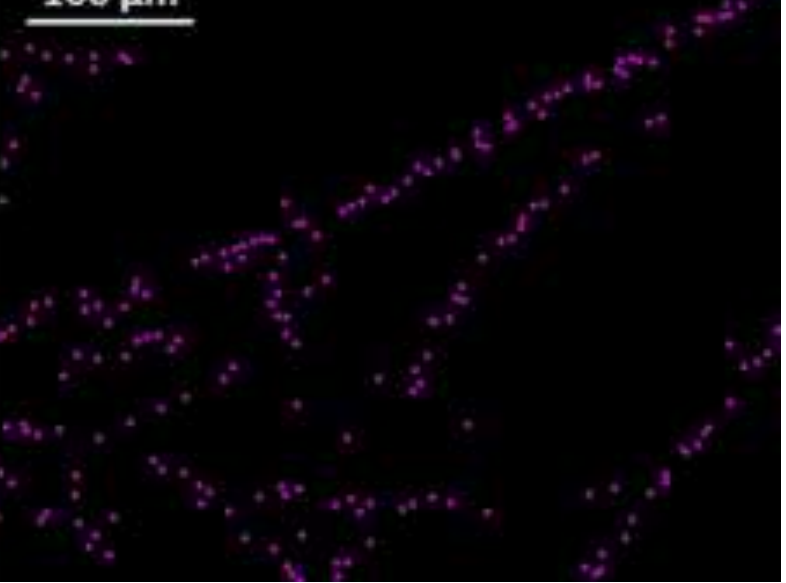

